\title{
Analytic model of upper tropospheric clouds in the tropical Hadley cell
}

\author{
Kyoko K. Tanaka ${ }^{1}$, Tetsuo Yamamoto ${ }^{1}$, Sei-ichiro Watanabe ${ }^{2}$, and Kensuke Nakajima ${ }^{3}$ \\ ${ }^{1}$ Institute of Low Temperature Science, Hokkaido University, Sapporo 060-0819, Japan \\ ${ }^{2}$ Department of Earth and Planetary Sciences, Nagoya University, Nagoya 464-8601, Japan \\ ${ }^{3}$ Department of Earth and Planetary Sciences, Faculty of Sciences, Kyushu University, Fukuoka 812-8581, Japan
}

(Received December 27, 2006; Revised December 7, 2007; Accepted December 7, 2007; Online published March 3, 2008)

\begin{abstract}
We have developed a two-dimensional analytic model that describes the behavior of upper tropospheric clouds in the tropical Hadley cell. The behavior of the model is characterized by two dimensionless parameters: one is proportional to the temperature lapse rate, and the other is relevant to the initial altitude of the cloud particles. We derived analytic expressions for the motion and evaporation of the cloud particles and calculate various cloud properties, such as the cloudiness and the column water content. We found that the outflow from the convective regions spreads out and generates a cirrus layer whose coverage has a maximum at the tropopause: the cloudiness is as large as $0.5-1$ in the vicinity of the tropopause for small cloud particles with radii of less than $5 \mu \mathrm{m}$. We suggest that the thin cirrus clouds observed near the tropopause in the tropic region are formed by the advection of cloud particles supplied from the ITCZ. Because of its simpleness, the present model may play a role in diagnosing cloud properties in climate models that are used to study climate changes over a long time span.
\end{abstract}

Key words: Sub-visible cirrus, cloudiness, evaporation of cloud particles, Hadley circulation.

\section{Introduction}

Many observations have revealed optically thin or subvisible cirrus clouds (SVCs) near the tropopause in the tropical regions. Much of our knowledge of SVCs comes from the occasional monitoring campaigns involving groundbased lidar and high-altitude aircraft (e.g., Heymsfield and McFarquhar, 1986). More recently, a global climatology of SVCs has been developed by the SAGE II satellite (Wang et al., 1996). Seasonal mean statistics have shown that SVCs frequently occur over a wide region of the tropics around $35 \mathrm{~N}$ to $20 \mathrm{~S}$; they have also revealed that SVCs extends over $\sim 1000 \mathrm{~km}$ in the layer from 14 to $17 \mathrm{~km}$ in altitude and with optical thickness typically in the range $10^{-3}$ to $10^{-1}$ (Wang et al., 1996; Comstock et al., 2002). The observations also showed that the cloud thickness and optical depth decrease with increasing latitude. More tenuous clouds, named Ultrathin Tropical Tropopause Clouds (UTTCs), with optical depths around $10^{-4}$ have also been observed in the vicinity of the tropical cold point tropopause (Winker and Trepte, 1998; Luo et al., 2003). Luo et al. (2003) found that UTTCs persist for many hours as a thin cloud layer of thickness of only 200-300 m just below the tropopause. These thin cirrus clouds play a potentially important role both as an essential element in the Earth's radiation budget and as an agent to dehydrate the uppermost troposphere.

Several mechanisms have been proposed for formation of SVCs and UTTCs. Danielsen (1982) and Sherwood and Dessler (2000) explained the origin of these clouds as remnants of the deep convective systems. Lilly (1988) investi-

Copyright (C) The Society of Geomagnetism and Earth, Planetary and Space Sciences (SGEPSS); The Seismological Society of Japan; The Volcanological Society of Japan; The Geodetic Society of Japan; The Japanese Society for Planetary Sciences; TERRAPUB gated cirrus outflow from deep convection and showed that the spreading of cirrus anvils is sensitive to radiation. Peter et al. (2003) proposed a mechanism that forces ice particles into a thin layer by a balance between upwelling and sedimentation of the particles. Jensen et al. (1996) considered two possible scenarios for the formation of thin cirrus at the tropical tropopause: outflow from cumulonimbus cirrus anvils and ice nucleation driven by slow vertical motion or shear turbulent mixing. They concluded that both mechanisms for thin cirrus formation seem plausible.

Jensen et al. (1996) investigated the evolution of the cumulonimbus cirrus anvil near the tropopause using oneand two-dimensional cloud models and showed that large amounts of ice water are transported to the upper troposphere and generate extensive cirrus outflow anvils. They pointed out that the optical depth of cirrus cloud and cloudiness depend on various quantities, such as the initial ice water content and the horizontal wind, however, these researchers did not investigate these dependencies in detail.

Jensen et al. (2001) also examined in situ nucleation of ice crystals, which is a more plausible explanation of the thinness and horizontally homogeneous appearance of these clouds. They suggested that if air rises slowly across the tropical tropopause, optically thin clouds with very low ice crystal number densities will form near the tropopause. However, despite the observational and theoretical studies mentioned above, no agreement has yet been reached on the formation mechanism of various types of tropical upper tropospheric cirrus. It may be worth considering the behavior of these various types of cirrus clouds, including SVCs and UTTCs, in relation to the overall structure of large-scale circulation in the tropics.

The formation of cirrus in the upper troposphere is also related to water vapor transport and the distribution of hu- 
midity in the atmosphere. Earlier observational studies revealed that the circulation transports water vapor effectively and causes relative humidity to peak sharply near the tropopause (Sherwood, 1996). With a numerical modeling approach using a cumulus ensemble model, Iwasa et al. (2002) showed that the air within the cumulus updraft region can go out to the quiescent subsidence region through the cumulus flank maintaining an almost saturated state at various vertical levels. One would expect cloud particles may also be ejected out of the cumulus over a wide-spread area if cloud particles follow similar trajectories as vapor.

Here, we propose a two-dimensional analytic model of the Hadley cell and examine the climatological behavior of upper tropospheric cloud particles, focusing on SVCs and UTTCs. Our model includes the evaporation of cloud particles in descending air parcels, which is a key process in determining the cloudiness and the column water content in the cirrus layers. We show that thin cirrus with high coverage is formed near the tropopause as a result of the long horizontal paths taken by air parcels from convective regions. In Section 2, we describe the model and develop its formulation. In Section 3, we present the results on the motion and evaporation processes of the cloud particles and discuss the cloudiness and the thickness of the cirrus layers. A summary and concluding remarks are given in Section 4.

\section{The Model}

\subsection{Model description}

The Hadley cell is a relatively simple overturning circulation, with rising motion near the equator, poleward motion near the tropopause, sinking motion in the subtropics, and an equator-ward return flow near the surface. The region in which the equator-ward moving surface flows cover and rise is known as the inter-tropical convergence zone (ITCZ), a high-precipitation band of thunderstorms. In this study, the Hadley cell is simply assumed to be described by a steady two-dimensional circulation (Held and Hou, 1980). The assumption may seem to be too simple to reproduce the Hadley cell, which consists of various space structures with various time scales. Certainly the flow is not steady: the active cumuli repeat the generation and disappearance in the ITCZ and the circulation is not steady within a short time interval. However, if the tropical region is considered within the long time-scale of the circulation ( $\sim$ a month), one can imagine the steady-state circulation of the Hadley cell where active cumuli stay steady in the ITCZ. We regard the steady-state circulation as the climatological Hadley cell and study the cloudiness and the cloud water contents in the upper troposphere in the climatological Hadley cell.

Figure 1 illustrates our model of the Hadley cell and the motion of air parcels in it. The scale and the time span of the circulation are a few thousand kilometers and tens of days, respectively. We model the zonally averaged climatological distributions of cloud and the water contents. As a first step, we ignore any east-west or temporal variability. In the ITCZ, strong upward air motion produces large amounts of cloud and rain particles. A large portion of the cloud particles falls down as rains within a short time during and after the ascent, but a fraction of the cloud particles streams out horizontally from the side of the ITCZ advected

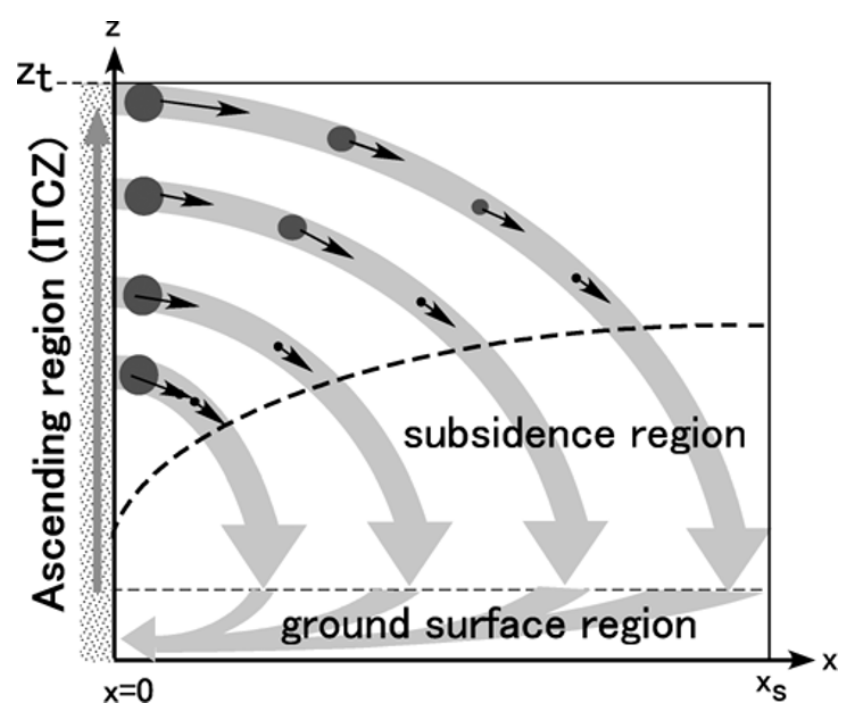

Fig. 1. Motion of air parcels containing cloud particles along the Hadley circulation. The cloud particles stream out horizontally from the ITCZ. They evaporate along the stream lines (shaded arrows) and disappear at the altitudes where the stream lines cross with the extinction line (thick dashed curve).

by the divergent flow beneath the tropopause. The air parcel subsequently descends slowly due to radiative cooling, while the cloud particles in the air parcel evaporate. The air parcel that reaches the ground surface region returns to the lower latitudes and takes up water vapor from the sea surface. Finally, the air parcel containing enough water vapor ascends again in the ITCZ.

The two-dimensional atmosphere is longitudinally symmetric. We take the $x$-axis along the latitude direction and the $z$-axis along the vertical direction, with the origin at the bottom of the ITCZ (see Fig. 1). We divide the circulation cell into three areas - the ascending region, the subsidence region, and the ground surface region-as shown in Fig. 1. In the subsidence region, the cloud particles evaporate in the descending air parcel and disappear at some altitude. The horizontal scale of the descending region is much larger than that of the ascending region in the ITCZ. The cloudiness and the cloud water content are determined by the behavior of the cloud particles in the descending region and their concentration when they leave the ITCZ. In this study, we calculate the motion and evaporation processes of the cloud particles and determine the time-averaged cloudiness and water cloud content.

\subsection{Formulation}

Consider a moist atmosphere of mass density $\rho$ consisting of dry air, vapor, and cloud particles. The mass conservation equation for the moist air is given by

$$
\frac{\partial \rho}{\partial t}+\frac{\partial}{\partial x}(\rho u)+\frac{\partial}{\partial z}(\rho w)=0
$$

where $u$ and $w$ are the northward and vertical velocities, respectively. The cloud droplets are supposed to be ice in the upper layer cloud, which is the focus of our study. We consider small cloud particles that completely follow the motion of the air parcel; the deviation of their motion from that of the air parcel will be examined in Section 4. We 
consider single-size cloud particles in the air parcel for simplicity and assume that the number of cloud particles in an air parcel is kept constant, ignoring their coalescence and fragmentation and the loss due to rain fall. Mass conservations for the vapor and the cloud particles are then given, respectively, by

$$
\begin{gathered}
\frac{\partial}{\partial t}\left(\chi_{\mathrm{v}} \rho\right)+\frac{\partial}{\partial x}\left(\chi_{\mathrm{v}} \rho u\right)+\frac{\partial}{\partial z}\left(\chi_{\mathrm{v}} \rho w\right)=E, \\
\frac{\partial}{\partial t}\left(\chi_{\mathrm{c}} \rho\right)+\frac{\partial}{\partial x}\left(\chi_{\mathrm{c}} \rho u\right)+\frac{\partial}{\partial z}\left(\chi_{\mathrm{c}} \rho w\right)=-E,
\end{gathered}
$$

where $E$ is the evaporation rate of the cloud particles, $\chi_{\mathrm{c}}$ is mass concentration of the the cloud particles, and $\chi_{\mathrm{v}}$ is mass concentration of the water vapor expressed by

$$
\chi_{\mathrm{v}}=\frac{\rho_{\mathrm{v}}}{\rho}
$$

in terms of $\rho$ and $\rho_{\mathrm{v}}$, mass density of the water vapor. With the use of Eq. (1), Eqs. (2) and (3) reduce, respectively, to

$$
\begin{aligned}
& \frac{d \chi_{\mathrm{v}}}{d t}=\frac{\partial \chi_{\mathrm{v}}}{\partial t}+u \frac{\partial \chi_{\mathrm{v}}}{\partial x}+w \frac{\partial \chi_{\mathrm{v}}}{\partial z}=\frac{E}{\rho}, \\
& \frac{d \chi_{\mathrm{c}}}{d t}=\frac{\partial \chi_{\mathrm{c}}}{\partial t}+u \frac{\partial \chi_{\mathrm{c}}}{\partial x}+w \frac{\partial \chi_{\mathrm{c}}}{\partial z}=-\frac{E}{\rho},
\end{aligned}
$$

where $d / d t$ is the Lagrangian time derivative along the stream line.

We assume that, in the subsidence region, the atmospheric circulation is regulated by the radiative balance (Sarachik, 1978; Betts and Ridgway, 1988; Iwasa et al., 2002) expressed by

$$
-c_{\mathrm{p}}\left(\frac{d T}{d t}\right)_{\mathrm{rad}}=-g w-c_{\mathrm{p}} \frac{d T}{d z} w-\frac{L}{m_{\mathrm{v}}} \frac{d \chi_{\mathrm{v}}}{d z} w,
$$

where $T$ is the atmospheric temperature, $c_{\mathrm{p}}$ is heat capacity per unit mass of dry air at a constant pressure, $L$ is latent heat of evaporation of cloud particles per mole of water molecules, $m_{\mathrm{v}}$ is molecular weight of water, and $g$ is the gravitational acceleration. The LHS of Eq. (7) expresses the radiative cooling of the air parcel. On the RHS, the first and second terms indicate the release of the gravitational energy due to the descent and the resultant compressional heating, respectively, and the third term indicates the cooling due to evaporation of the cloud particles. It should be noted that the third term on the RHS is nonzero in the saturated area of the upper region of the subsidence area. From Eq. (7), the vertical velocity $w$ is given by

$$
-w=-\frac{1}{\beta}\left(\frac{d T}{d t}\right)_{\mathrm{rad}}
$$

with

$$
\beta=\frac{d T}{d z}+\frac{g}{c_{\mathrm{p}}}+\frac{L}{m_{\mathrm{v}} c_{\mathrm{p}}} \frac{d \chi_{\mathrm{v}}}{d z} .
$$

Note that both $w$ and $\beta$ depend only on $z$ for the atmosphere we are discussing. Assuming $\rho$ and $w$ are independent of $x$ and integrating Eq. (1) with respect to $x$ under $\partial \rho / \partial t=0$, we obtain the horizontal velocity $u$ as

$$
u=\frac{x_{\mathrm{s}}-x}{\rho} \frac{d(\rho w)}{d z}
$$

where $x_{\mathrm{s}}$ is a scale of the circulation cell, namely, the horizontal distance from the location where $u=0$. The position of a cloud particle $(\xi, \zeta)$ at time $t$ is determined by

$$
\begin{aligned}
& \dot{\xi}=u(\xi, \zeta)=\frac{x_{\mathrm{s}}-\xi}{\rho} \frac{d}{d \zeta}(\rho w), \\
& \dot{\zeta}=w(\zeta) .
\end{aligned}
$$

Eliminating $t$ from Eqs. (11) and (12), the stream line is given by

$$
\frac{\xi}{x_{\mathrm{s}}}=1-\frac{\rho_{0} w_{0}}{\rho(\zeta) w(\zeta)}
$$

where $\rho_{0}=\rho\left(z_{0}\right)$ and $w_{0}=w\left(z_{0}\right)$ with $z_{0}$ being an initial altitude of the cloud particle. Evaporation of a cloud particle is controlled by the diffusion of water vapor in the air (Pruppacher and Klett, 1977). The evaporation rate for the cloud particle of radius $r$ and the number density $n_{\mathrm{c}}$ in the vapor of the mass concentration $\chi_{\mathrm{v}}$ is expressed by

$$
E=4 \pi n_{\mathrm{c}} \rho r D\left(\chi_{\mathrm{v}}^{*}-\chi_{\mathrm{v}}\right),
$$

where $D$ is the diffusion constant of water molecules in the air, and $\chi_{\mathrm{v}}^{*}$ is the mass concentration of a saturated vapor. Substituting Eq. (14) into Eq. (6) with the use of the relation $r=\left(3 \rho \chi_{\mathrm{c}} / 4 \pi n_{\mathrm{c}} \rho_{\mathrm{w}}\right)^{1 / 3}$, the time variation of the mass concentration of cloud particles is expressed by

$$
\frac{d \chi_{\mathrm{c}}}{d t}=\left(4 \pi n_{\mathrm{c}}\right)^{2 / 3}\left(\frac{3 \rho}{\rho_{\mathrm{w}}}\right)^{1 / 3} D \chi_{\mathrm{c}}^{1 / 3}\left(\chi_{\mathrm{c}}+\chi_{\mathrm{v}}^{*}-\chi_{\mathrm{tot}}\right),
$$

where $\rho_{\mathrm{w}}$ is density of a cloud particle, and $\chi_{\text {tot }}$ is the total mass concentration given by

$$
\chi_{\text {tot }}=\text { const }=\chi_{\mathrm{v}}+\chi_{\mathrm{c}} .
$$

\subsection{The case of a constant lapse rate}

We consider a stratified atmosphere in the steady state. According to the typical models of a tropical atmosphere (e.g., McClatchey et al., 1971; Folkins et al., 1999), the temperature lapse rate is about 6.5 to $8 \mathrm{~K} \mathrm{~km}^{-1}$ and is nearly constant at the altitude of $5-17 \mathrm{~km}$ in middle and upper troposphere. For a constant lapse rate, the temperature $T$, the pressure $p$, and the density $\rho$ are expressed (Iwasa $e t$ al., 2002) using a parameter $\Gamma$ as

$$
\begin{aligned}
& \frac{T}{T_{\mathrm{t}}}=1+\Gamma \frac{z_{\mathrm{t}}-z}{H_{\mathrm{t}}}, \\
& \frac{p}{p_{\mathrm{t}}}=\left(1+\Gamma \frac{z_{\mathrm{t}}-z}{H_{\mathrm{t}}}\right)^{1 / \Gamma}, \\
& \frac{\rho}{\rho_{\mathrm{t}}}=\left(1+\Gamma \frac{z_{\mathrm{t}}-z}{H_{\mathrm{t}}}\right)^{(1-\Gamma) / \Gamma},
\end{aligned}
$$

where $T_{\mathrm{t}}, p_{\mathrm{t}}$ and $\rho_{\mathrm{t}}$ are those at the altitude of the tropopause $z_{\mathrm{t}}$, and $H_{\mathrm{t}}$ is the scale height for the pressure at $z=z_{\mathrm{t}}$ given by

$$
H_{\mathrm{t}}=-\left(\frac{d z}{d \ln p}\right)_{z_{\mathrm{t}}}=\frac{R T_{\mathrm{t}}}{m g}
$$


where $R$ is the gas constant and $m$ is mean molecular weight of the dry air. Equation (17) can be applied well to the tropical atmosphere only in the middle and upper troposphere. That is sufficient to address the cirrus cloud issues of the paper.

Since the time-scales of evaporation and condensation of water vapor are very short compared to that of the motion of cloud particles, one may expect that the water vapor is almost saturated $\left(\chi_{\mathrm{v}}=\chi_{\mathrm{v}}^{*}\right)$ at any altitude at which as the cloud particles survive. Approximating the vapor pressure of water by the Clapeyron-Clausius relation given by $p_{\mathrm{v}}^{*}(T)=p_{\mathrm{v}}^{*}\left(T_{\mathrm{s}}\right) e^{-L / R\left(1 / T-1 / T_{\mathrm{s}}\right)}$ with $L=50.9 \mathrm{~kJ} \mathrm{~mol}^{-1}$ for ice (Satoh, 2002), $\chi_{\mathrm{v}}^{*}$ is expressed as

$$
\chi_{\mathrm{v}}^{*}=\frac{m_{\mathrm{v}}}{m} \frac{p_{\mathrm{v}}^{*}}{p}=\frac{m_{\mathrm{v}}}{m} \frac{p_{\mathrm{v}}^{*}\left(T_{\mathrm{s}}\right)}{p} \exp \left\{-\frac{L}{R}\left(\frac{1}{T}-\frac{1}{T_{\mathrm{s}}}\right)\right\}
$$

where $p_{\mathrm{v}}^{*}\left(T_{\mathrm{s}}\right)=6.1 \times 10^{2} \mathrm{~Pa}$ for $T_{\mathrm{s}}=273.15 \mathrm{~K}$. Then, $\beta$ given by Eq. (9) is calculated to be

$$
\beta=\frac{m g}{R}\left[\frac{R}{m c_{\mathrm{p}}}-\Gamma-\frac{L \chi_{\mathrm{v}}^{*}}{m_{\mathrm{v}} c_{\mathrm{p}} T}\left(\frac{\Gamma L}{R T}-1\right)\right]
$$

for the atmosphere characterized by Eqs. (17)-(19).

The radiative cooling rate $-(d T / d t)_{\text {rad }}$ can be approximated by the Newtonian cooling expressed by $(d T / d t)_{\mathrm{rad}}=\left(T_{\mathrm{t}}-T\right) / \tau_{\mathrm{R}}$ for an optically thin atmosphere in the present case, where $\tau_{\mathrm{R}}$ is the radiative relaxation time estimated by

$$
\tau_{\mathrm{R}} \simeq \frac{c_{\mathrm{p}}}{12\left(\kappa_{\mathrm{v}} \chi_{\mathrm{v}}+\kappa_{\mathrm{c}} \chi_{\mathrm{c}}\right) \sigma T_{\mathrm{R}}^{3}},
$$

where $T_{\mathrm{R}}$ is the radiative equilibrium temperature and $\kappa_{\mathrm{V}}$ and $\kappa_{\mathrm{c}}$ are the mass absorption coefficients of the water vapor and the cloud particles (Satoh, 2002). Assuming $T_{\mathrm{R}} \simeq T_{\mathrm{t}}(\simeq 180 \mathrm{~K})$ and $\kappa_{\mathrm{v}} \chi_{\mathrm{v}} \ll \kappa_{\mathrm{c}} \chi_{\mathrm{c}} \simeq 2 \times 10^{-3}$ (Iwasa et al., 2002), $\tau_{\mathrm{R}}$ is about 15 days, which is consistent with detailed calculations taking into account the radiative transfer (Roewe and Liou, 1978). We approximate the vertical velocity as

$$
w=-\frac{1}{\beta \tau_{\mathrm{R}}}\left(T-T_{\mathrm{t}}\right)
$$

Figure 2 shows the vertical velocity profiles for $T_{\mathrm{t}}=180 \mathrm{~K}$ and three lapse rates, indicating that the $z$-gradient of $w$ is nearly constant in upper troposphere $(10 \lesssim z \leq 17 \mathrm{~km})$. This is due to the fact that the term including $\chi_{\mathrm{v}}^{*}$ in $\beta$ given by Eq. (22) is much smaller than the other terms, implying that $\beta \simeq$ const at high $z$. We can thus approximate $w$ at the high altitude as

$$
w=\alpha\left(z-z_{\mathrm{t}}\right),
$$

where $\alpha^{-1}$ is a time-scale at the descent of an air parcel, and is given by

$$
\begin{aligned}
\alpha=\frac{m g \Gamma}{R \beta \tau_{\mathrm{R}}}= & 2.5 \times 10^{-6}\left(\frac{\Gamma}{0.19}\right)\left(\frac{\beta}{2 \mathrm{~K} \mathrm{~km}^{-1}}\right)^{-1} \\
& \times\left(\frac{\tau_{\mathrm{R}}}{15 \text { days }}\right)^{-1} \mathrm{~s}^{-1}
\end{aligned}
$$

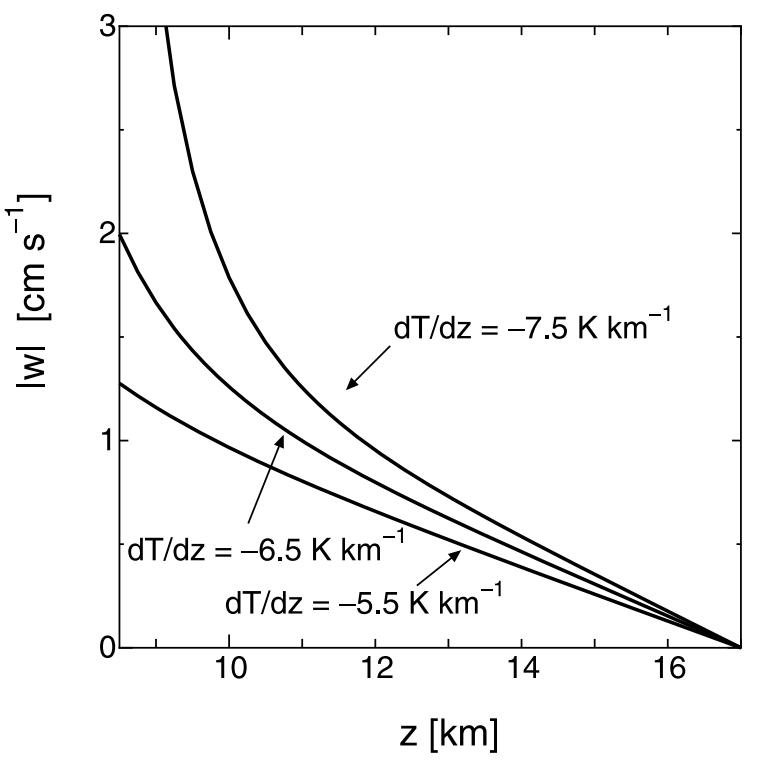

Fig. 2. Absolute values of vertical velocity $|w|$ versus altitude $z$ estimated by Eq. (24).

from Eqs. (24) and (17). Substituting Eqs. (19) and (25) into Eq. (10), the horizontal velocity $u$ is expressed by

$$
u=\alpha\left[1+\frac{(1-\Gamma)\left(z_{\mathrm{t}}-z\right)}{H_{\mathrm{t}}+\Gamma\left(z_{\mathrm{t}}-z\right)}\right]\left(x_{\mathrm{s}}-x\right) .
$$

We set

$$
\tau=\alpha t, \quad \varepsilon=\frac{T_{0}}{T_{\mathrm{t}}}-1=\Gamma\left(\frac{z_{\mathrm{t}}-z_{0}}{H_{\mathrm{t}}}\right),
$$

where $T_{0}$ is an initial temperature of the cloud particle. Then, the position of a cloud particle is calculated to be

$$
\begin{aligned}
\frac{\xi}{x_{\mathrm{s}}} & =1-\left(\frac{1+\varepsilon}{1+\varepsilon e^{\tau}}\right)^{(1-\Gamma) / \Gamma} e^{-\tau}, \\
\frac{\zeta}{z_{\mathrm{t}}} & =1-\left(1-\frac{z_{0}}{z_{\mathrm{t}}}\right) e^{\tau},
\end{aligned}
$$

by integrating Eq. (25) with respect to $t$ and substituting the result into Eq. (13). The stream line given by Eq. (13) is expressed as

$$
1-\frac{\xi}{x_{\mathrm{s}}}=\frac{z_{\mathrm{t}}-z_{0}}{z_{\mathrm{t}}-\zeta}\left[\frac{(1+\varepsilon)\left(z_{\mathrm{t}}-z_{0}\right)}{z_{\mathrm{t}}-z_{0}+\varepsilon\left(z_{\mathrm{t}}-\zeta\right)}\right]^{(1-\Gamma) / \Gamma} .
$$

Note that the stream line is independent of $\alpha$. The time variation of the mass concentration $\chi_{c}$ of cloud particles given by Eq. (15) is expressed in a dimensionless form by

$$
-v \frac{d \chi_{\mathrm{c}}}{d \tau}=\left(1+\varepsilon e^{\tau}\right)^{(1-\Gamma) / \Gamma} \chi_{\mathrm{c}}^{1 / 3}\left(\chi_{\mathrm{c}}+\chi_{\mathrm{v}}^{*}-\chi_{\mathrm{tot}}\right)
$$

with

$$
v=\alpha t_{\mathrm{D}}, \quad t_{\mathrm{D}}=\left(4 \pi n_{\mathrm{ct}}\right)^{-2 / 3} D^{-1}\left(\frac{3 \rho_{\mathrm{t}}}{\rho_{\mathrm{w}}}\right)^{-1 / 3},
$$

since $n_{\mathrm{c}} \propto \rho$ because of the conservation of the number of cloud particles in the air parcel, where $n_{\mathrm{ct}}=n_{\mathrm{c}}\left(z_{\mathrm{t}}\right)$. From 
Eq. (21) together with Eqs. (17) and (18), $\chi_{\mathrm{v}}^{*}$ in Eq. (32) is expressed as

$$
\chi_{\mathrm{v}}^{*}=\chi_{\mathrm{v} 0}^{*}\left(\frac{1+\varepsilon}{1+\varepsilon e^{\tau}}\right)^{1 / \Gamma} \exp \left[\frac{L}{R T_{0}}\left(1-\frac{1+\varepsilon}{1+\varepsilon e^{\tau}}\right)\right]
$$

where $\chi_{\mathrm{v} 0}^{*}$ is $\chi_{\mathrm{v}}^{*}$ at $\tau=0$.

Solutions of Eq. (32) are characterized by the nondimensional parameters $v, \Gamma$ the nondimensional lapse rate, and $\varepsilon$ relevant to the initial altitude of the cloud particles. Since $l_{\mathrm{ct}}=n_{\mathrm{ct}}^{-1 / 3}$ is a mean distance of cloud particles, we have $D t_{\mathrm{D}} \sim l_{\mathrm{ct}}^{2}\left(l_{\mathrm{ct}} / r\right) \equiv l^{2}$. This implies that $t_{\mathrm{D}}$ defined by Eq. (33) is a time scale for water vapor molecules to diffuse by distance $l$ in the air. The parameter $v$ is the ratio of the diffusion time scale $t_{\mathrm{D}}$ to the descending time scale $\alpha^{-1}$. The time $t_{\mathrm{D}}$ and the parameter $v$ are evaluated to be

$$
\begin{aligned}
t_{\mathrm{D}}= & 1.2\left(\frac{D}{0.3 \mathrm{~cm}^{2} \mathrm{~s}^{-1}}\right)^{-1}\left(\frac{n_{\mathrm{ct}}}{20 \mathrm{~cm}^{-3}}\right)^{-2 / 3} \\
& \times\left(\frac{\rho_{\mathrm{t}} / \rho_{\mathrm{w}}}{10^{-4}}\right)^{-1 / 3} \mathrm{~s} \\
v= & 3 \times 10^{-6}\left(\frac{\Gamma}{0.19}\right)\left(\frac{\beta}{2 \mathrm{~K} \mathrm{~km}^{-1}}\right)^{-1}\left(\frac{\tau_{\mathrm{R}}}{15 \text { days }}\right)^{-1} \\
& \times\left(\frac{D}{0.3 \mathrm{~cm}^{2} \mathrm{~s}^{-1}}\right)^{-1}\left(\frac{n_{\mathrm{c}}}{20 \mathrm{~cm}^{-3}}\right)^{-2 / 3} \\
& \times\left(\frac{\rho_{\mathrm{t}} / \rho_{\mathrm{w}}}{10^{-4}}\right)^{-1 / 3} .
\end{aligned}
$$

Note that $v$ is as small as $10^{-6}$ to $10^{-5}$, implying that $\chi_{\mathrm{c}}-\chi_{\mathrm{v}}^{*}-\chi_{\text {tot }} \simeq 0$ in Eq. (32). This confirms the validity of the approximation $\chi_{\mathrm{v}}=\chi_{\mathrm{v}}^{*}$ used in deriving Eq. (22).

\section{Results and Discussion}

We take a constant lapse rate of $6.5 \mathrm{~K} \mathrm{~km}^{-1}$ (i.e., $\Gamma=$ $0.19), v=2 \times 10^{-6}, z_{\mathrm{t}}=17 \mathrm{~km}$, and $T_{\mathrm{t}}=182 \mathrm{~K}$ as typical values. For the size of the Hadley circulation cell of $x_{\mathrm{s}}=3000 \mathrm{~km}$, our model yields an initial horizontal velocity of $\alpha x_{\mathrm{s}}=6 \mathrm{~m} \mathrm{~s}^{-1}$ at $z=z_{\mathrm{t}}$; this value is consistent with the observation (e.g., Newell et al., 1972). The timescale $t_{*}$ for the air parcel at $x=0$ and $z=z_{\mathrm{t}}$ to reach $x_{*}$ is given by

$$
t_{*}=\int_{0}^{x_{*}} \frac{d x}{u(x)}=\frac{1}{\alpha} \ln \left(\frac{x_{\mathrm{s}}}{x_{\mathrm{s}}-x_{*}}\right) .
$$

For example, $t_{*}$ is 10 days for the parcel to reach $2500 \mathrm{~km}$ and 20 days to reach $2900 \mathrm{~km}$.

Figure 3 illustrates a typical time variation of the altitude $z$ given by Eq. (30) and the mass concentration $\chi_{c}$ of cloud particles obtained by solving Eq. (32) together with the temperature $T$ given by Eq. (17) and the mass concentration of the vapor, $\chi_{\mathrm{v}}$ for $z_{0}=12 \mathrm{~km}$ and $\chi_{\mathrm{c}}(0)=1 \times 10^{-4}$. Figure 3(b) shows that the mass concentration of cloud particles decreases with time due to the elevation of their temperatures and that they evaporate completely at $10.5 \mathrm{~km}$. We note in Fig. 3(b) that the vapor is almost saturated $\left(\chi_{\mathrm{v}}=\right.$ $\left.\chi_{\mathrm{v}}^{*}\right)$, and approximate $\chi_{\mathrm{c}}$ by

$$
\chi_{\mathrm{c}}(\tau)=\chi_{\mathrm{tot}}-\chi_{v}^{*}
$$
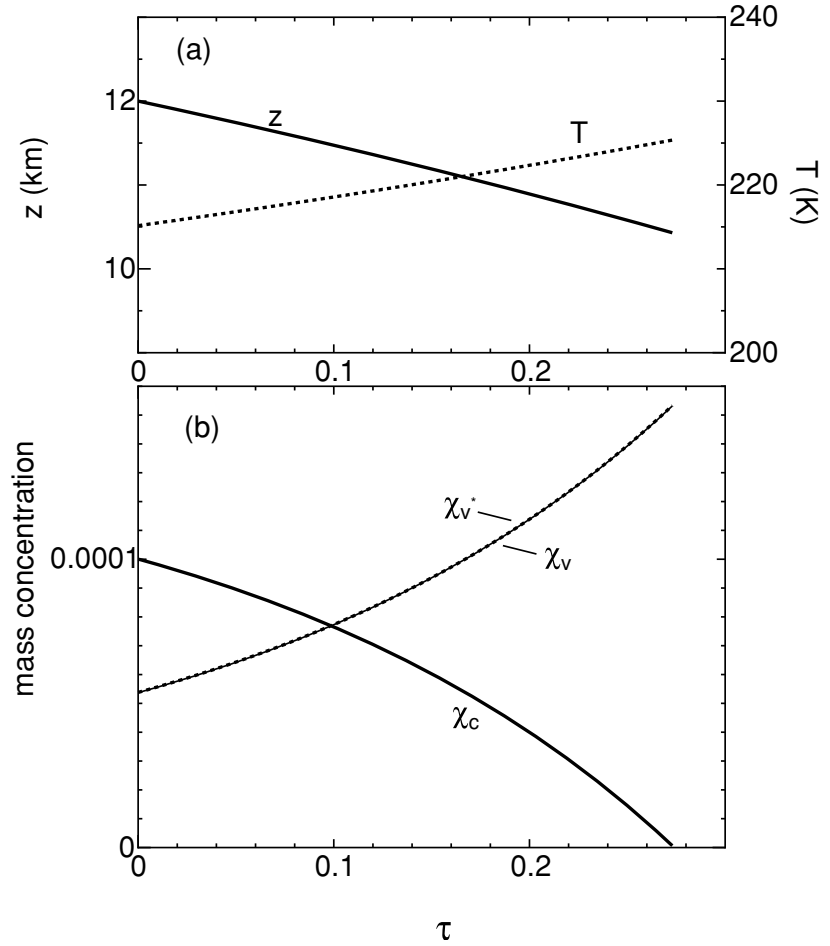

Fig. 3. (a) Altitude $z$ of cloud particles and the temperature $T$ of the surrounding air versus time $\tau$ for their initial altitude of $z_{0}=12 \mathrm{~km}$ and initial concentration of $\chi_{\mathrm{c}}(0)=1 \times 10^{-4}$. (b) Time variation of the mass concentrations of the vapor, $\chi_{\mathrm{v}}$, and the cloud particles, $\chi_{\mathrm{c}}$. The mass concentration of saturated vapor, $\chi_{\mathrm{v}}^{*}$, is also shown for comparison. We took the constant lapse rate of $6.5 \mathrm{~K} \mathrm{~km}^{-1}, v=6 \times 10^{-6}, z_{\mathrm{t}}=17 \mathrm{~km}$, and $T_{\mathrm{t}}=182 \mathrm{~K}$.

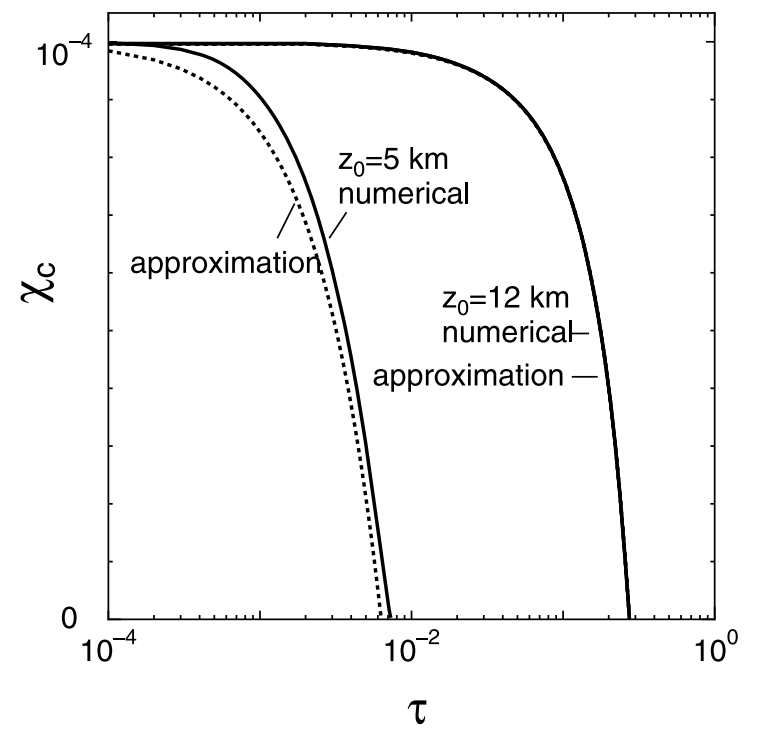

Fig. 4. Comparison between the numerical solution (solid curves) of the mass concentration of cloud particles, $\chi_{\mathrm{c}}$, and its approximation (dotted curves) given by Eq. (38) together with Eq. (34) for the initial altitude $z_{0}=5$ and $12 \mathrm{~km}$. Other parameter values are the same as in Fig. 3. For $z_{0}=12 \mathrm{~km}$, the numerical and the approximate lines are indistinguishable in the scale of the figure.

Figure 4 compares the approximation (Eq. (38)) with $\chi_{\mathrm{c}}$ obtained by solving Eq. (32) numerically, indicating that Eq. (38) reproduces the numerical solution very well unless the initial heights are low $\left(z_{0} \lesssim 5 \mathrm{~km}\right)$. We assume $\chi_{\mathrm{v}}=\chi_{\mathrm{v}}^{*}$ 

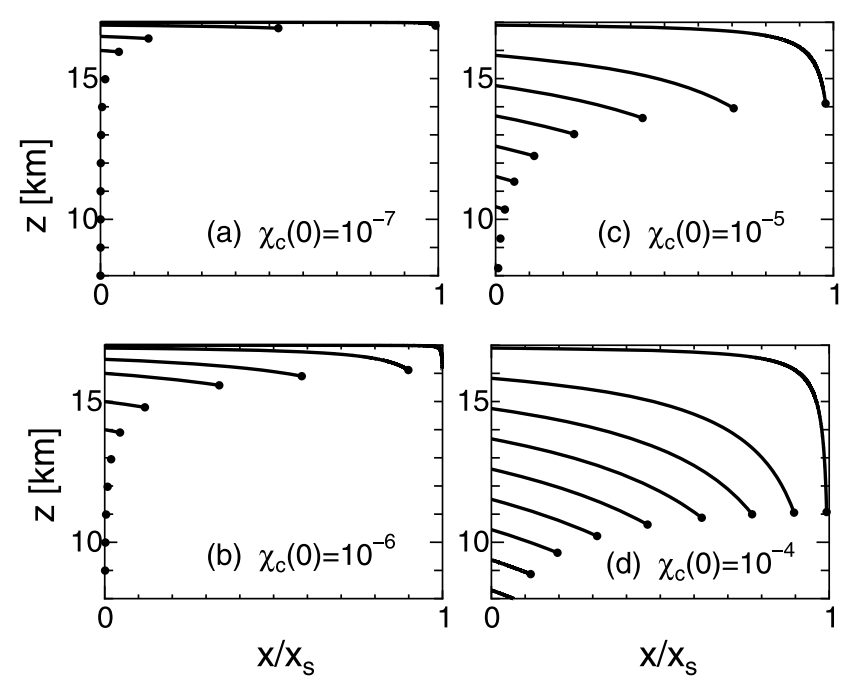

Fig. 5. Trails of the motion of cloud particles starting from various initial heights for $\chi_{\mathrm{c}}(0)=1 \times 10^{-7}(\mathrm{a}), \chi_{\mathrm{c}}(0)=1 \times 10^{-6}(\mathrm{~b}), 1 \times 10^{-5}(\mathrm{c})$, and $1 \times 10^{-4}(\mathrm{~d})$. The initial mass concentrations $\chi_{\mathrm{c}}(0)$ are taken to be uniform with height. The filled circles indicate the positions where the cloud particles evaporate completely.

in the air parcels including cloud particles hereafter.

Figure 5 shows the trails of cloud particles for $\chi_{\mathrm{c}}(0)=$ $1 \times 10^{-7}, 1 \times 10^{-6}, 1 \times 10^{-5}$, and $1 \times 10^{-4}$, where we took uniform vertical distributions for $\chi_{\mathrm{c}}(0)$. Note that at high altitudes, such as in the vicinity of the tropopause, the cloud particles can reach close to the edge of the circulation cell against evaporation because their evaporation is very slow owing to the low temperatures at the high altitudes. On the other hand, they do not reach the middle or lower troposphere. In terms of the cloudiness defined by

$$
C(z)=x_{\mathrm{e}} / x_{\mathrm{s}}
$$

with $x_{\mathrm{e}}$ being the horizontal distance of complete evaporation of cloud particles at a given altitude $z, C(z)$ is almost unity at high altitudes even if $\chi_{\mathrm{c}}(0)$ is small, whereas $C(z)$ is 0 to 0.1 in the middle and the lower layer.

The column cloud water content $\Sigma_{\mathrm{c}}$ and optical depth $\tau_{\mathrm{c}}$ of the cloud layer are given by

$$
\begin{aligned}
\Sigma_{\mathrm{c}}(x) & =\int_{0}^{z_{\mathrm{t}}} \rho(z) \chi_{c}(x, z) d z, \\
\tau_{\mathrm{c}}(x) & =\int_{0}^{z_{\mathrm{t}}} \kappa(x, z) \rho(z) \chi_{c}(x, z) d z,
\end{aligned}
$$

where $\kappa$ is the mass absorption coefficient of cloud particles. In the calculation of the optical depth $\tau_{\mathrm{c}}$, we take the initial size of $5 \mu \mathrm{m}$ and the complex refractory index $m=1.3$ for ice particles at the near infrared wavelength of $1 \mu \mathrm{m}$ (Warren, 1984). We calculate $\kappa$ by the Mie theory, taking into account the size decrease in the cloud particles during the fall. Figure 6 indicates that, except near the ITCZ, the column water content and the optical depth range are from $8 \times 10^{-8}$ to $2 \times 10^{-3} \mathrm{~g} \mathrm{~cm}^{-2}$ and from $10^{-4}$ to 1 for $1 \times 10^{-7} \leq \chi_{\mathrm{c}}(0) \leq 1 \times 10^{-5}$, respectively, and their variations with $x$ are almost identical.

Many observations revealed frequent occurrences of SVCs covering a wide region of the tropics. The observations show the presence of SVCs at altitudes between 14

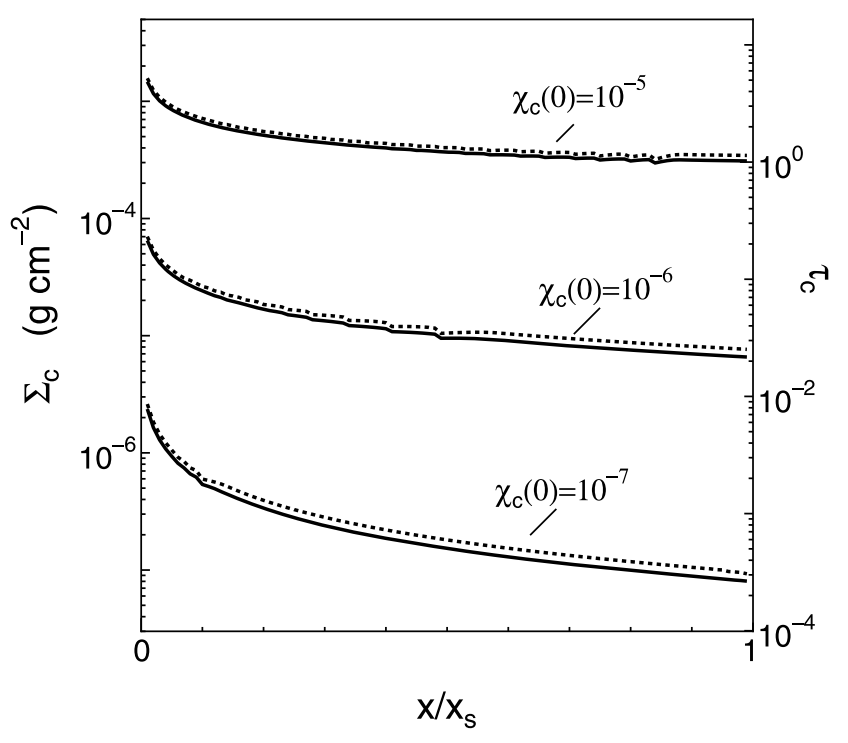

Fig. 6. Horizontal distribution of column cloud water content (solid curves, left axis) and optical depth (dotted curves, right axis) for $\chi_{\mathrm{c}}(0)=1 \times 10^{-7}, 1 \times 10^{-6}$, and $1 \times 10^{-5}$.

and $17 \mathrm{~km}$ with a thickness of about $3 \mathrm{~km}$ (Wang et al., 1996). Our model suggests that these thin clouds can be maintained by the advection of the cloud particles supplied from the ITCZ. The values of $\chi_{\mathrm{c}}(0)$ between $10^{-6}$ and $10^{-5}$ can explain the thickness of the SVCs. In addition to the SVCs, the more tenuous cloud layer UTTCs with a thickness of 200-300 m appear temporally in the vicinity of the tropical cold-point tropopause and are observed in the absence of SVCs (Winker and Trepte, 1998; Luo et al., 2003). The thickness of the UTTCs is estimated from $z_{\mathrm{t}}-z_{\mathrm{et}}$, where $z_{\text {et }}$ is the altitude at which the cloud particles starting from altitude $z_{\mathrm{t}}$ evaporate completely $\left(\chi_{\mathrm{c}}=0\right)$. Since $\left(z_{\mathrm{t}}-z_{\mathrm{et}}\right) / H_{\mathrm{t}} \ll 1$ in the relevant situation, the thickness of the UTTCs is evaluated approximately to be

$$
z_{\mathrm{t}}-z_{\mathrm{et}}=H_{\mathrm{t}}\left(\frac{\Gamma L}{R T_{\mathrm{t}}}-1\right)^{-1} \ln \left[\frac{\chi_{\mathrm{c}}(0)}{\chi_{\mathrm{v}}^{*}\left(T_{\mathrm{t}}, \rho_{\mathrm{t}}\right)}+1\right]
$$

from Eq. (21) with the use of Eqs. (17) and (19). The thickness $z_{\mathrm{t}}-z_{\text {et }}$ is $0.12,0.8,2.6$, and $4.8 \mathrm{~km}$ for $\chi_{\mathrm{c}}(0)=$ $1 \times 10^{-7}, 1 \times 10^{-6}, 1 \times 10^{-5}$ and $1 \times 10^{-4}$, respectively, where $\chi_{\mathrm{v}}^{*}\left(T_{\mathrm{t}}, \rho_{\mathrm{t}}\right)=8 \times 10^{-7}$ for $T_{\mathrm{t}}=182 \mathrm{~K}$. These thicknesses reproduce the results shown in Fig. 5 with an error of less than $20 \%$. We note that the $\chi_{\mathrm{c}}(0)$ values as small as $2 \times 10^{-7}$ to $3.5 \times 10^{-7}$ can explain the UTTC thickness of 200-300 m. Also, as shown in Fig. 6, the model with $\chi_{\mathrm{c}}(0) \sim 10^{-7}$ predicts the optical depth of $\tau_{\mathrm{c}} \sim 10^{-4}$, which is consistent with the observed value for UTTC.

For comparison, we show an example of the observed vertical distribution for $\chi_{\mathrm{c}}(0)$. Figure 7 shows the mass concentration of the ice cloud particles estimated by the TRMM Microwave Imager (TMI) on board the Tropical Rainfall Measuring Mission (TRMM) satellite (Kummerow et al., 1998). The $\chi_{\mathrm{c}}(0)$ profile (courtesy of M. Yamamoto and K. Matsuzaki) is that averaged out the values of $\chi_{\mathrm{c}}(0)$ at positions of latitude from 0 to $10 \mathrm{~N}$ during the summer time (June-August) in 1998-2003. $\chi_{c}(0)$ increases with 


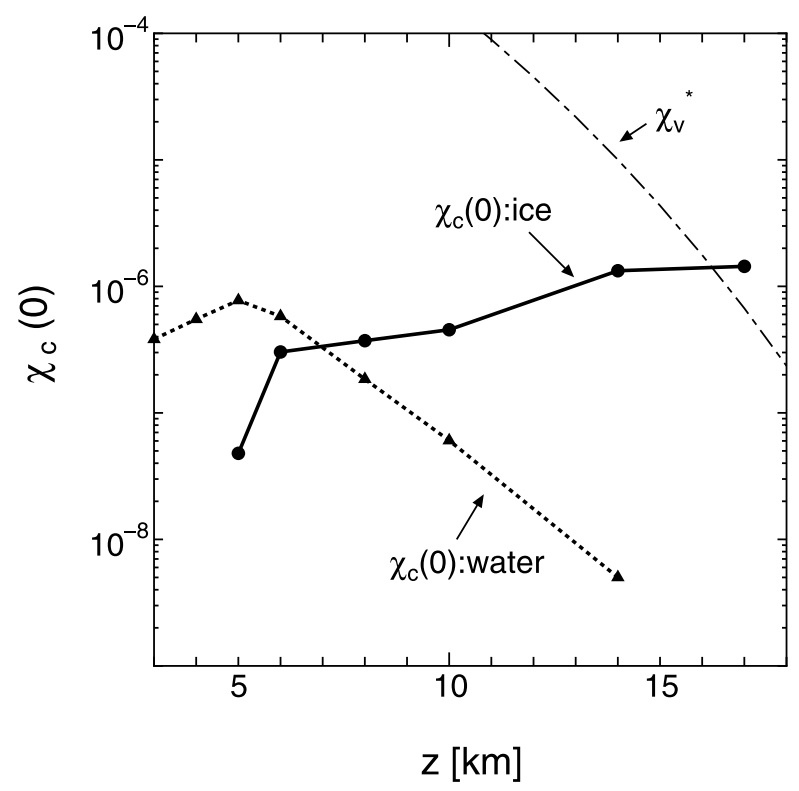

Fig. 7. Vertical profile of the mass concentration of cloud particles obtained by an observation obtained by TRMM satellite data (Kummerow et al., 1998) provided by M. Yamamoto and K. Matsuzaki (private communications). The observation shows the $\chi_{\mathrm{c}}(0)$ that was averaged out the values of $\chi_{\mathrm{c}}(0)$ at the positions of latitude from 0 to $10 \mathrm{~N}$ during the summer time (June-August) in 1998-2003. The solid line with closed circles shows the $\chi_{\mathrm{c}}(0)$ of ice cloud particles. For comparison, $\chi_{\mathrm{v}}^{*}$ for the lapse rate of $6.5 \mathrm{~K} \mathrm{~km}^{-1}$, the surface temperature of $293 \mathrm{~K}$ (dotted-dashed line), and $\chi_{\mathrm{c}}(0)$ of water cloud particles (dotted line with closed triangles) are shown.

altitude and is almost constant at high altitudes; $\chi_{\mathrm{c}}(0)$ is about $1.4 \times 10^{-6}$ for $14 \leq z \leq 17 \mathrm{~km}$, which can explain the thickness and the optical depth of SVCs.

Finally, we illustrate how the results are modified if we take into account the velocity of the cloud particles relative to the air parcel. Actually, the determination of the motions of the vapor and cloud particles having relative velocity is a rather complicated problem. We present here a rough estimate of the deviation of their motions by giving the relative velocity. Given the relative velocity $u_{\mathrm{r}}$ and $w_{\mathrm{r}}$, the position of a cloud particle may be written as

$$
\xi_{\mathrm{c}}=\xi+\xi_{\mathrm{r}}, \quad \zeta_{\mathrm{c}}=\zeta+\zeta_{\mathrm{r}}
$$

with

$$
\xi_{\mathrm{r}}=\int_{0}^{t} u_{\mathrm{r}} d t, \quad \zeta_{\mathrm{r}}=\int_{0}^{t} w_{\mathrm{r}} d t .
$$

Substituting Eq. (42) into Eqs. (29) and (30), one obtains

$$
\begin{aligned}
& \frac{\xi_{\mathrm{c}}-\xi_{\mathrm{r}}}{x_{\mathrm{s}}}=1-\left(\frac{1+\varepsilon}{1+\varepsilon e^{\tau}}\right)^{(1-\Gamma) / \Gamma} e^{-\tau}, \\
& \frac{\zeta_{\mathrm{c}}-\zeta_{\mathrm{r}}}{z_{\mathrm{t}}}=1-\left(1-\frac{z_{0}}{z_{\mathrm{t}}}\right) e^{\tau} .
\end{aligned}
$$

This set of the equations is expressed in terms of the parameter $\tau$ and represents the stream line of cloud particles having the relative velocity. Here we set $u_{\mathrm{r}}=0$ because of the rapid decrease in the relative velocity in the horizontal direction due to drag of the atmosphere. For the vertical

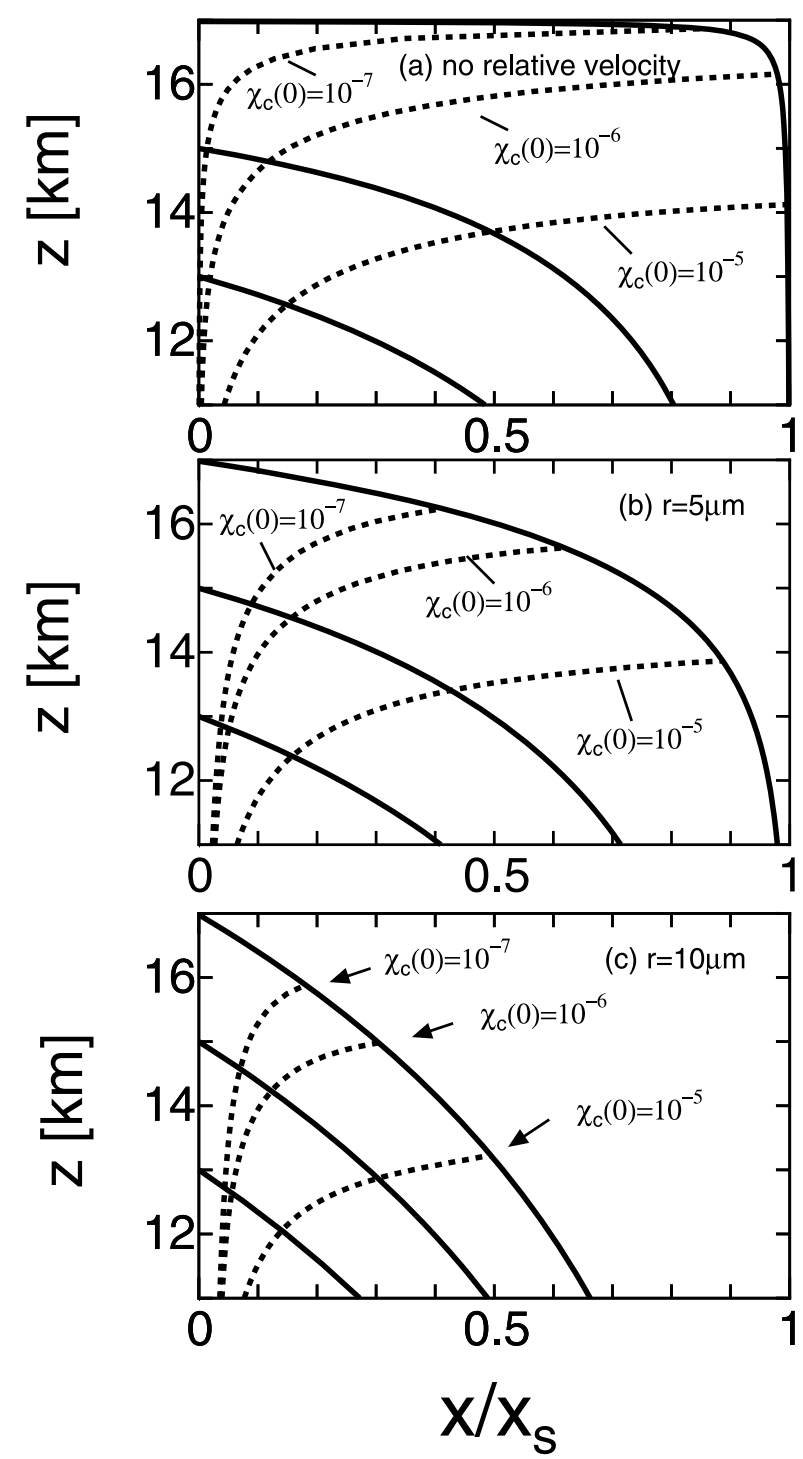

Fig. 8. Stream lines of cloud particles and their extinction lines. The solid curves show the stream line of cloud particles for no relative velocity (a) and those for radii 5 (b) and $10 \mu \mathrm{m}$ (c). We set $\alpha=2 \times 10^{-6} \mathrm{~s}^{-1}$ (see Eq. (26)). The dotted curves indicate the extinction lines of cloud particles.

relative velocity, we take a constant terminal velocity estimated by the Stokes law (e.g., Pruppacher and Klett, 1977), which yields

$$
\begin{aligned}
-w_{\mathrm{r}} \simeq & 1.1 \times 10^{-2}\left(\frac{r}{1 \mu \mathrm{m}}\right)^{2} \\
& \times\left(\frac{\eta}{2 \times 10^{-4} \mathrm{~g} \mathrm{~cm}^{-1} \mathrm{~s}^{-1}}\right)^{-1} \mathrm{~cm} \mathrm{~s}^{-1}
\end{aligned}
$$

where $\eta$ is the viscosity coefficient of the atmosphere.

Figure 8 shows the stream lines of cloud particles having relative velocities together with those with no relative velocity for comparison. The dotted lines, which we call the extinction lines, are the ones connecting the endpoints of the trails where the cloud particles evaporate completely for the uniform distribution of $\chi_{c}(0)$. In the Appendix, we show the analytic derivation of the extinction lines, where we take $\chi_{\mathrm{v}}=\chi_{\mathrm{v}}^{*}$ into the calculation. A cloud particle 


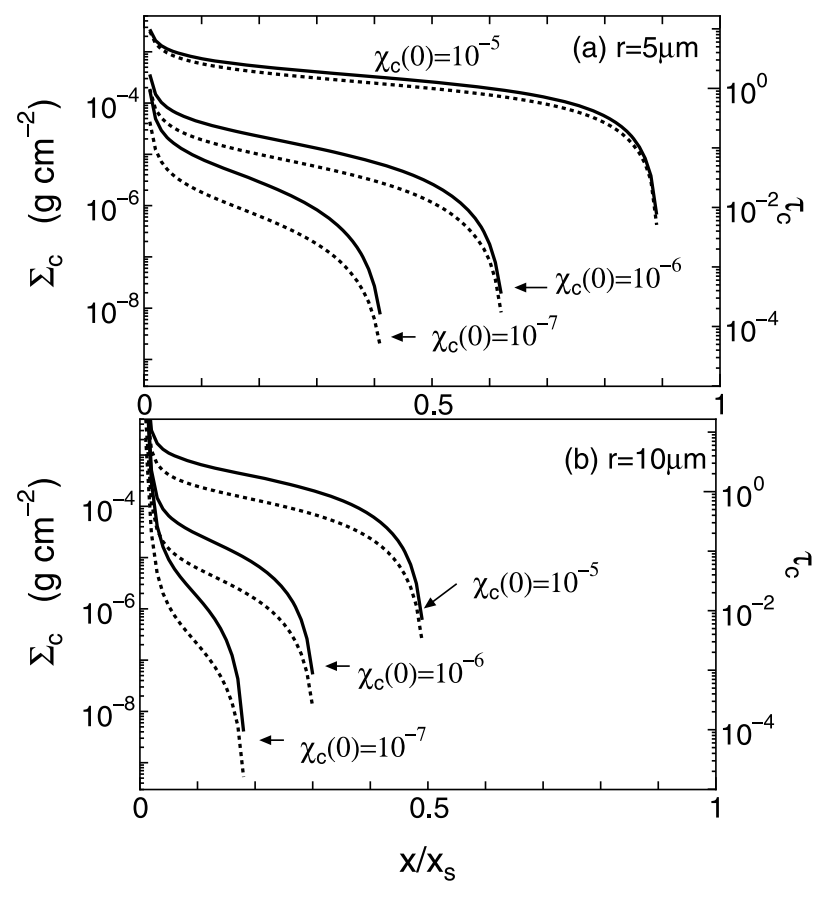

Fig. 9. Horizontal distribution of column cloud water content (solid curves, left axis) and optical depth (dotted curves, right axis) for $\chi_{\mathrm{c}}(0)=1 \times 10^{-7}, 1 \times 10^{-6}$, and $1 \times 10^{-5}$ in the case that the effect of the cloud particle sedimentation is included for radii 5 (a) and $10 \mu \mathrm{m}$ (b).

starting from $z=z_{0}$ disappears at the cross point, $\left(x_{\mathrm{e}}, z_{\mathrm{e}}\right)$, of the stream line and the extinction line. Note that, for given $\chi_{\mathrm{c}}(0)$ and $z_{0}$, the altitudes of the extinction point $z_{\mathrm{e}}$ are almost independent of the radii $r$ of the cloud particles. In other words, the cloud particles of different radii starting from the same initial altitude $z_{0}$ disappear at almost the same altitudes. The reason for this is that there arises a "critical" altitude below which the cloud particles evaporate in a very short time, since the evaporation rate is a very sensitive function of temperature. On the other hand, the horizontal distance $x_{\mathrm{e}}$ is smaller than that in the case of no relative velocity for the same $\chi_{\mathrm{c}}(0)$ and $z_{0}$. Although the extinction altitude $z_{\mathrm{e}}$ is almost insensitive to the particle radii, large particles reach the extinction point within a shorter time than small particles because of their large vertical speed $\left|w_{\mathrm{r}}\right|$. As a result, the horizontal distance $x_{\mathrm{e}}$ attained by large particles is shorter than that attained by small particles since the horizontal velocity $u$ is independent of the radius.

The cloudiness $C(z)$ as a function of $z$ for given $\chi_{\mathrm{c}}(0)$ consists of two lines: one is the stream line starting from $z_{\mathrm{t}}$ for $z>z_{\mathrm{et}}$, and the other is the extinction line for $z<z_{\mathrm{et}}$ (see Fig. 8). The maximum cloudiness is given by $C_{\max }=$ $x_{\text {et }} / x_{\mathrm{s}}$, where $x_{\mathrm{et}}$ is the horizontal distance of the extinction point. $C_{\max }$ equals unity for the case of no relative velocity, as seen from Fig. 8(a). For the case in which particle sedimentation is included, $C_{\max }$ decreases with increasing the radius $r$. For $r=5 \mu \mathrm{m}$ (Fig. 8(b)), which is a typical size of the particles in UTTCs (Peter et al., 2003), $C_{\text {max }}$ varies from 0.4 to 0.9 for $10^{-7} \lesssim \chi_{\mathrm{c}}(0) \lesssim 10^{-5}$.

The present evaluation of the cloudiness may be underestimated because we ignore the size decrease of the cloud particles during the fall; the actual vertical velocity $w_{\mathrm{c}}$ will be between $w$ and $w+w_{\mathrm{r}}$. Even if we take the size decrease into account, however, the stream lines are almost identical with those in which it was ignored except near the extinction point because, as a matter of fact, the cloud particles evaporate only near the extinction point, as mentioned above.

Figure 9 show the horizontal distribution of column cloud water content and optical depth for $\chi_{\mathrm{c}}(0)=1 \times 10^{-7}, 1 \times$ $10^{-6}$, and $1 \times 10^{-5}$ in the case that the effect of the cloud particle sedimentation is included. A comparison of Figs. 6 and 9 reveals that the column cloud water content and optical depth decrease with increasing $x$. On the other hand, the observations show that the optical depth and the cloud thickness decrease with increasing distance from the equator. This latitude dependency is consistent with the results of our model.

\section{Summary and Concluding Remarks}

We have developed a simple model of the tropical circulation which enables us to calculate the advection and evaporation of cloud particles. This model assumes a constant lapse rate of the atmosphere and is practically characterized by the two dimensionless parameters, $\Gamma$ and $\varepsilon$, reflecting the lapse rate and the initial altitude of the cloud particles, respectively. We have derived analytic expressions describing the motion of the evaporating cloud particles and various cloud properties, such as cloudiness and optical depth.

We have applied the model to the upper tropospheric clouds in the tropical Hadley cell. The key finding of the paper is that outflows from convective regions are expected to spread out with coverage that increases sharply near the tropopause, offering a plausible explanation for the high coverage of thin cirrus currently found there. The cloudiness in the high layer is very large because small cloud particles survive against evaporation and extend considerably in the horizontal direction during the slow descending motion driven by the weak radiative cooling. On the other hand, the cloud particles starting from low altitudes in the ITCZ evaporate efficiently in the middle and the lower layers at $z \leq 10 \mathrm{~km}$, leading to small cloudiness in these layers. In particular, the cloudiness in the vicinity of the tropopause, where the radiative cooling is very weak, is almost unity even if the amount of the cloud particles supplied from the ITCZ is very small, provided that their sizes are so small that the relative motion to the gas is negligible. This is consistent with the observations of the thin cirrus clouds discovered in the wide area near the tropopause in the tropic region. Our results suggest that the thin cirrus clouds are formed by the advection of the cloud droplets supplied from the cumulus system. The cloudiness $C\left(z_{\mathrm{e}}\right)$ depends on the size of the cloud particles; $C\left(z_{\mathrm{e}}\right)$ is large for the small particles $(r \lesssim 5 \mu \mathrm{m})$, while $C\left(z_{\mathrm{e}}\right)$ is considerably small for the large particles $(r \gtrsim 10 \mu \mathrm{m})$.

Due to neglect of zonal inhomogeneity and temporal variability, the present model may somewhat over-estimate the cloudiness. However, based on the following argument, we believe that the present result is qualitatively correct, at least for the case without the sedimentation of cloud particles. Although we present Fig. 1 for clarity, what we actually examined is the behavior of each of the air parcel com- 
ing out of cumulus, which is independent of the behavior of other parcels. This treatment is quite appropriate, since the parcels descend without interacting with each other. Therefore, the behavior of each parcel is not affected by whether the model's geometry is two dimensional or three dimensional; the parcels ejected from the cloud at the same vertical level have the same thermodynamics properties after descending to the same altitude. In an extreme case where the cloud forms randomly in both the temporal and spatial sense, the paths of air parcels shall be entangled. Even in such a case, the thermodynamic evolution of the air parcels is not affected by the entanglement. If a descending parcel is intercepted by a developing cloudy updraft, its thermodynamic property does change. However, considering the generally small coverage of active cumulus updrafts, such an event of interception shall be rare. Consequently, we can have a reasonably correct estimate of the vertical distribution of the statistical average of cloudiness by horizontally averaging the result with the present two-dimensional model. The end result shall have most features common to the solutions we obtained in this paper-for example, a significant peak of cloudiness near the tropopause.

In the case of the sedimentation of cloud particles, the situation becomes slightly uncertain. This is a particularly true if a large amount of precipitation particles fall into and evaporate in the air parcel; in such a case, the humidity and cloud water content of the air parcel are estimated improperly in the model. However, such a situation is mainly occurs in the lower or middle layer of convective clouds, and the influence of precipitation would not so effective for the tropopause region that we are concerned with. In addition, considering that the extinction altitude is a weak function of relative humidity, as pointed out at the end of the previous section, the statistical average of cloudiness can again be estimated by the horizontally average of the present results with sedimentation velocity (i.e., Fig. 8).

There is a possibility that the results change if Walker circulation dominates. Even in such a case, however, the north-south flow still exists in the circulation to supplement the descent in the Hadley cell, and cirrus clouds would form in the wide area. Of course, to verify this aspect, we should investigate the influence of asymmetric structure using a more sophisticated model. Also, east-west nonuniformity of the cloud activity exists in the real atmosphere. Since active convection in the tropics generates the flows primarily in the east-west direction in the vicinity of the tropopause due to the Earth's rotation (e.g., Gill, 1980), the air parcel is also transported rapidly in the east-west direction. As a result, the humidity and the temperature tend to be symmetric in the upper layer. In addition, the position of the ITCZ is displaced in the south-north direction from the equator. This may cause an error in the distribution of humidity and the cloud in the vicinity of rising region. However, the important result of this research is that the upper layer cloud extends broadly, covering the region far from the ITCZ, so that the influence of the south-north displacement in the ITCZ would be small.

Although the present model simplifies the actual complex phenomena considerably, it may serve as a basis to diagnose the cloud properties in climate models because of its simpleness and the resultant minimal amount of the computational costs. This is true in particular for 'simple Earth-system models' (e.g., Lenton, 2000; Ichii et al., 2003), which deal with the climate changes for a long timespan. In actual applications, the incorporation of the present model into the simple Earth-system models would require additional tasks. For example, one needs to specify the vertical profile of $\chi_{c}(0)$, which is the end result of the complex interactions between cloud microphysical processes and meso- and convective scale motions. Combinations of the present model with other models, such as the cumulus ensemble models (e.g., Nakajima and Matsuno, 1988; Held et al., 1993; Sui et al., 1994) will result in the development of more realistic models for the formation and disappearance of the upper tropospheric clouds in the tropical region. The model presented here may also be suitable for predicting the formation and extinction of clouds in planetary atmospheres, where reliable information on cloud microphysics and atmospheric motion are hard to obtain.

Acknowledgments. We thank M. Yamamoto and K. Matsuzaki for providing the TRMM data, T. Shibata for helpful discussions, and Y.-Y. Hayashi and M. Satoh for valuable comments. We also thank anonymous reviewers for invaluable comments for improving the original manuscript. This work was partly supported by the 21Century COE Program "the Sun-Earth-Life Interactive System (SELIS)" of Nagoya University.

\section{Appendix A.}

We derive the extinction line, taking into account the relative velocity between the cloud particle and the air parcel. Instead of Eq. (3), the mass conservation for the cloud particles is given by

$$
\frac{\partial}{\partial t}\left(\chi_{\mathrm{c}} \rho\right)+\frac{\partial}{\partial x}\left(\chi_{\mathrm{c}} \rho u_{\mathrm{c}}\right)+\frac{\partial}{\partial z}\left(\chi_{\mathrm{c}} \rho w_{\mathrm{c}}\right)=-E .
$$

Using Eqs. (2) and (3), the equation for $\chi_{c}$ is given by

$$
\frac{d \chi_{\mathrm{c}}}{d z}+g(z) \chi_{\mathrm{c}}=-\frac{w}{w_{\mathrm{c}}} \frac{d \chi_{\mathrm{v}}^{*}}{d z}
$$

where $g(z)$ is a function expressed as

$$
g(z)=\frac{w_{\mathrm{r}}}{w_{\mathrm{c}}} \frac{d \ln \rho}{d z} .
$$

The general solution for Eq. (A.2) is given by

$$
\begin{aligned}
\chi_{\mathrm{c}}(z)= & -\int_{z_{0}}^{s} d s \frac{w}{w_{\mathrm{c}}} \frac{d \chi_{\mathrm{v}}^{*}}{d z} \exp \left[-\int_{s}^{z} d t g(t)\right] \\
& +\chi_{\mathrm{c}}\left(z_{0}\right) \exp \left[-\int_{z_{0}}^{z} d t g(t)\right],
\end{aligned}
$$

where $\chi_{\mathrm{c}}=\chi_{\mathrm{c}}\left(z_{0}\right)$ at $z=z_{0}$. Using Eq. (19) and $w_{\mathrm{c}}=$ $\alpha\left(z-z_{\mathrm{t}}\right)+w_{\mathrm{r}}$, we obtain the following relations

$$
\begin{gathered}
-\int_{z_{0}}^{s} d t g(t)=\ln f(z, s), \\
-\int_{z_{0}}^{z} d t g(t)=\ln f\left(z, z_{0}\right),
\end{gathered}
$$

where

$$
f(x, y) \equiv\left(\frac{w_{\mathrm{c}}(x) T(y)}{w_{\mathrm{c}}(y) T(x)}\right)^{\theta}, \quad \theta \equiv \frac{(1-\Gamma) w_{\mathrm{r}}}{\alpha H_{\mathrm{t}}+\Gamma w_{\mathrm{r}}} .
$$


Using Eqs. (A.5) and (A.6), $\chi_{\mathrm{c}}$ is expressed as

$$
\begin{aligned}
\chi_{\mathrm{c}}(z)= & -\int_{z_{0}}^{z} d s \frac{w(s)}{w_{\mathrm{c}}(s)} \frac{d \chi_{\mathrm{v}}^{*}}{d s} f(z, s) \\
& +\chi_{\mathrm{c}}\left(z_{0}\right) f\left(z, z_{0}\right) .
\end{aligned}
$$

Furthermore, the first term on the RHS of Eq. (A.7) is written as

$$
\begin{aligned}
-\int_{z_{0}}^{z} d s \frac{w(s)}{w_{\mathrm{c}}(s)} \frac{d \chi_{\mathrm{v}}^{*}}{d s} f(z, s)= & -\left[\frac{w(s)}{w_{\mathrm{c}}(s)} f(z, s) \chi_{\mathrm{v}}^{*}(s)\right]_{z_{0}}^{z} \\
& +\int_{T_{0}}^{T} d T \frac{d s}{d T} \chi_{\mathrm{v}}^{*}(s) \\
& \times \frac{\partial}{\partial s}\left[\frac{w(s)}{w_{\mathrm{c}}(s)} f(z, s)\right] . \text { (A. }
\end{aligned}
$$

Substituting Eq. (A.8) into Eq. (A.7), we obtain the solution given by

$$
\begin{aligned}
\chi_{\mathrm{c}}(z)= & f\left(z, z_{0}\right)\left(\frac{w\left(z_{0}\right)}{w_{\mathrm{c}}\left(z_{0}\right)} \chi_{\mathrm{v}}^{*}\left(z_{0}\right)+\chi_{\mathrm{c}}\left(z_{0}\right)\right)-\frac{w}{w_{\mathrm{c}}} \chi_{\mathrm{v}}^{*}(z) \\
& -\frac{R T^{2} H_{\mathrm{t}}}{\Gamma L T_{\mathrm{t}}} \chi_{\mathrm{v}}^{*}(z)\left(\frac{\alpha w_{\mathrm{r}}}{w_{\mathrm{c}}^{2}}+\frac{w}{w_{\mathrm{c}}} g(z)\right),
\end{aligned}
$$

where the second term on RHS of Eq. (A.8) is calculated as

$$
\begin{aligned}
& \int_{T_{0}}^{T} d T \frac{d s}{d T} \chi_{\mathrm{v}}^{*}(s) \frac{\partial}{\partial s}\left[\frac{w(s)}{w_{\mathrm{c}}(s)} f(z, s)\right] \\
& \simeq-\frac{H_{\mathrm{t}}}{\Gamma T_{\mathrm{t}}} \frac{R T^{2}}{L} \chi_{\mathrm{v}}^{*}(T)\left[\frac{\partial}{\partial s}\left\{\frac{w(s)}{w_{\mathrm{c}}(s)} f(z, s)\right\}\right]_{s=z}
\end{aligned}
$$

Because the extinction line is determined by the condition $\chi_{\mathrm{c}}\left(z_{\mathrm{e}}\right)=0$ at $z=z_{\mathrm{e}}$, we obtain

$$
\begin{aligned}
\chi_{\mathrm{c}}\left(z_{0}\right)= & -\frac{w\left(z_{0}\right)}{w_{\mathrm{c}}\left(z_{0}\right)} \chi_{\mathrm{v}}^{*}\left(z_{0}\right)+\chi_{\mathrm{v}}^{*}\left(T_{\mathrm{e}}\right) f\left(z_{0}, z_{\mathrm{e}}\right)\left\{\frac{w\left(z_{\mathrm{e}}\right)}{w_{\mathrm{c}}\left(z_{\mathrm{e}}\right)}\right. \\
& \left.+\frac{R T_{\mathrm{e}}^{2} H_{\mathrm{t}}}{\Gamma L T_{\mathrm{t}} w_{\mathrm{c}}\left(z_{\mathrm{e}}\right)}\left(\frac{\alpha w_{\mathrm{r}}}{w_{\mathrm{c}}\left(z_{\mathrm{e}}\right)}+w\left(z_{\mathrm{e}}\right) g\left(z_{\mathrm{e}}\right)\right)\right\} .(
\end{aligned}
$$

From Eq. (A.11), we obtain the altitude $z_{\mathrm{e}}$ of the extinction point for given $z_{0}, \chi_{\mathrm{c}}\left(z_{0}\right)$, and $w_{\mathrm{r}}$. We also obtain the horizontal distance $x_{\mathrm{e}}$ of the extinction point from Eqs. (44) and (45) through the obtained $z_{\mathrm{e}}$.

\section{References}

Betts, A. K. and W. Ridgway, Coupling of the radiative, convective, and surface fluxes over the equatorial Pacific, J. Atmos. Sci., 45, 522-536, 1988

Comstock, J. M., T. P. Ackerman, and G. Mace, Ground-based lidar and radar remote sensing of tropical cirrus clouds at Nauru Island: cloud statistics and radiative impacts, J. Geophys. Res., 107(D23), 4714, 2002.

Danielsen, E. F., A dehydration mechanism for the stratosphere, Geophys. Res. Lett., 9, 605-608, 1982.

Folkins, I., M. Loewenstein, J. Podolske, S. J. Oltmans, and M. Proffitt, A barrier to vertical mixing at $14 \mathrm{~km}$ in the tropics: evidence from ozonesondes and aircraft measurements, J. Geophys. Res., 104, 22095$22102,1999$.

Gill, A. E., Some simple solutions for heat-induced tropical circulation, Ouart. J. Roy. Meteorol. Soc., 106, 447-462, 1980.

Held, I. M. and A. Y. Hou, Nonlinear Axially Symmetric Circulations in a Nearly Inviscid Atmosphere, J. Atmos. Sci., 37, 515-533, 1980.

Held, I. M., R. S. Hemler, and V. Ramaswamy, Radiative-convective equilibrium with explicit two-dimensional moist convection, J. Atmos. Sci., 50, 3909-3927, 1993.
Heymsfield, A. J. and G. M. McFarquhar, Ice particles observed in a cirriform cloud at $-83^{\circ} \mathrm{C}$ and implication for polar stratospheric clouds, J. Atmos. Sci., 43, 851-855, 1986.

Ichii, K., Y. Matsui, K. Murakami, T. Mukai, Y. Yamaguchi, and K. Ogawa, A simple global carbon and energy coupled cycle model for global warming simulation: sensitivity to the light saturation effect, Tellus, 55B, 676-691, 2003.

Iwasa, Y., Y. Abe, and H. Tanaka, Structure of the atmosphere in radiativeconvective equilibrium, J. Atmos. Sci., 59, 2197-2226, 2002.

Jensen, E. J., O. B. Toon, H. B. Selkirk, J. D. Spinhirne, and M. R. Schoeberl, On the formation and persistence of subvisible cirrus clouds near the tropical tropopause, J. Geophys. Res., 101, 21,361-21,375, 1996

Jensen, E. J., L. Pfister, A. S. Ackerman, O. B. Toon, and A. Tabazadeh, A conceptual model of the dehydration of air due to freeze-drying by optically thin, laminar cirrus rising slowly across the tropical tropopause, J. Geophys. Res., 106, 17,237-17,252, 2001.

Kummerow, C., W. Barnes, T. Kozu, J. Shiue, and J. Simpson, The tropical rainfall measuring mission (TRMM) sensor package, J. Atmos. Oceanic Technol., 15, 809-817, 1998.

Lenton, T. M., Land and ocean carbon cycle feedback effects on global warming in a simple Earth system model, Tellus, 52B, 1159-1188, 2000

Lilly, D. K., Cirrus outflow dynamics, J. Atmos. Sci., 45, 1594-1605, 1988.

Luo, B. P., Th. Peter, H. Wernli, S. Fueglistaler, M. Wirth, C. Kiemle, H. Flentje, V. A. Yushkov, V. Khattatov, V. Rudakov, A. Thomas, S. Borrmann, G. Toci, P. Mazzinghi, J. Beuermann, C. Schiller, F. Cairo, G. Di Don-Francesco, A. Adriani, C. M. Volk, J. Strom, K. Noone, V. Mitev, R. A. Mackenzie, K. S. Carslaw, T. Trautmann, V. Santacesaria, and L. Stefanutti, Ultrathin tropical tropopause clouds (UTTCs): II. Stabilization mechanisms, Atmos. Chem. Phys., 3, 1093-1100, 2003.

McClatchey, R. A., R. W. Fenn, J. E. A. Selby, F. E. Volz, and J. S. Garing, Optical properties of the atmosphere, Report AFCRL_71_0279, Air Force Cambridge Research Lab., Bedford, Massachussetts, 1971.

Nakajima, K. and T. Matsuno, Numerical experiments concerning the origin of cloud clusters in the tropical atmosphere, J. Meteor. Soc. Japan, 66, 309-329, 1988.

Newell, R. E., J. W. Kidson, D. G. Vincent, and G. J. Boer, The general circulation of the tropical atmosphere and interactions with extratropical latitudes, Cambridge, 1972.

Peter, Th., B. P. Luo, M. Wirth, C. Kiemle, H. Flentje, V. A. Yushkov, V. Khattatov, V. Rudakov, A. Thomas, S. Borrmann, G. Toci, P. Mazzinghi, J. Beuermann, C. Schiller, F. Cairo, G. Di Don-Francesco, A. Adriani, C. M. Volk, J. Strom, K. Noone, V. Mitev, R. A. Mackenzie, K. S. Carslaw, T. Trautmann, V. Santacesaria, and L. Stefanutti, Ultrathin tropical tropopause clouds (UTTCs): I. Cloud morphology and occurrence, Atmos. Chem. Phys., 3, 1083-1091, 2003.

Pruppacher, H. R. and J. D. Klett, Microphysics of clouds and precipitation, pp. 361-446, Kluwer academic publishers, Netherlands, 1977.

Roewe, D. and K.-N. Liou, Influence of cirrus clouds on the infrared cooling rate in the troposphere and lower stratosphere, J. Appl. Meteor., 17, 92-106, 1978.

Sarachik, E. S., Tropical sea surface temperature: An interactive onedimensional atmosphere ocean model, Dyn. Atmos. Oceans., 2, 455469, 1978.

Satoh, M., Atmospheric circulation dynamics and general circulation models, 643 pp, Springer-Praxis, 2002.

Sherwood, S. C., Maintenance of the free-tropospheric tropical water vapor distribution. Part I: Clear regime budget, J. Climate, 9, 2903-2918, 1996.

Sherwood, S. C. and A. E. Dessler, On the control of stratospheric humidity, Geophys. Res. Lett., 27, 2513-2516, 2000.

Sui, C. H., K. M. Lau, W. K. Tao, and J. Simpson, The tropical water and energy cycles in a cumulus ensemble model. Part I: Equilibrium climate, J. Atmos. Sci., 51, 711-728, 1994.

Wang, Pi-H., P. Minnis, M. P. McCormick, G. S. Kent, and K. M. Skeens, A 6-year climatology of cloud occurrence frequency from stratospheric aerosol and gas experiment II observations (1985-1990), J. Geophys. Res., 101, 29,407-29,429, 1996.

Warren, S. G., Optical constants of ice from the ultraviolet to the microwave, Appl. Optics., 23, 1206-1225, 1984.

Winker, D. M. and C. R. Trepte, Laminar cirrus observed near the tropical tropopause by LITE, Geophys. Res. Lett., 25, 3351-3354, 1998.

K. K. Tanaka (e-mail: kktanaka@lowtem.hokudai.ac.jp), T. Yamamoto, S.-i. Watanabe, and K. Nakajima 